\title{
CAPACIDAD EMBRIOGÉNICA DE CALLOS INDUCIDOS EN EJES EMBRIONARIOS CIGÓTICOS DE Agave angustifolia Haw
}

\author{
EMBRYOGENIC CAPACITY OF INDUCED CALLI ON \\ ZYGOTIC EMBRYONIC AXIS OF Agave angustifolia Haw
}

\author{
Amaury-Martín Arzate-Fernández ${ }^{1 \star}$ y Rafael Mejía-Franco ${ }^{1}$
}

\begin{abstract}
${ }^{1}$ Laboratorio de Biología Molecular Vegetal, Facultad de Ciencias Agrícolas, Universidad Autónoma del Estado de México-Campus "El Cerrillo". Carretera TolucaIxtlahuaca, km 11.5 entronque al Cerrillo Piedras Blancas. 50200, Toluca, Estado de México. Tel. 01 (722) 296 5516, 2965529,296 5531, Ext. 144.

*Autor para correspondencia: (amaury1963@yahoo.com.mx)
\end{abstract}

\section{RESUMEN}

El uso como explantes de ejes embrionarios cigóticos de semillas de agave mezcalero (Agave angustifolia Haw), permitió inducir embriones somáticos (ES) in vitro, previa formación de callos embriogénicos. Se probaron dos concentraciones de las sales Murashige y Skoog (MS), 25 y $100 \%$ de la original (MS-25 y MS-100), combinados con 0.0, 0.5, 1.0, 2.0 y $3.0 \mathrm{mg} \mathrm{L}^{-1}$ de ácido 2,4-diclorofenoxiacético (2,4-D), con 0.0 y $1.0 \mathrm{mg}$ $\mathrm{L}^{-1}$ de 6-benciladenina (BA), y con 30 y $60 \mathrm{~g} \mathrm{~L}^{-1}$ de sacarosa. La mitad de los tratamientos fueron incubados bajo un fotoperíodo de $16 \mathrm{~h}$ luz (38 $\mu \mathrm{mol} \mathrm{m} \mathrm{m}^{-2} \mathrm{~s}^{-1}$ y $\mathbf{8} \mathrm{h}$ de oscuridad, y la otra mitad en completa oscuridad, para un total de 80 tratamientos. La inducción de callo se observó a los 4 días (d) después de iniciado el cultivo (DDIC) en condiciones de luz y a los $5 \mathrm{~d}$ en condiciones de oscuridad, independientemente del tratamiento, excepto en donde no se adicionaron reguladores del crecimiento vegetal (RCV) y en los suplementados sólo con BA. La formación de ES se observó a los 100 DDIC; este proceso se vio favorecido en callos embriogénicos previamente inducidos en el medio MS-25 adicionado con $60 \mathrm{~g} \mathrm{~L}^{-1}$ de sacarosa, $3.0 \mathrm{mg} \mathrm{L}^{-1}$ de 2,4-D y 1.0 $\mathrm{mg} \mathrm{L}^{-1}$ de $\mathrm{BA}$, en condiciones de oscuridad. Se logró la germinación de todos los ES en el medio MS-50, $60 \mathrm{~g} \mathrm{~L}^{-1}$ de sacarosa y $8 \mathrm{~g} \mathrm{~L}^{-1}$ de agar, sin RCV, y se logró regenerar plantas completas de A. angustifolia a los 140 DDIC.

Palabras clave: Agave angustifolia, embriones somáticos, ácido 2,4-diclorofenoxiacético, 6-benciladenina.

\section{SUMMARY}

By using zygotic embryonic axis from seeds of agave mezcalero (Agave angustifolia $\mathrm{Haw}$ ) as explants, it was possible to induce embriogenic calli in vitro, and from these calli we obtained somatic embryos (SE). Two concentrations of the Murashige and Skoog (MS) medium were used, 25 and $100 \%$ concentrations (MS-25 and MS-100) combined with 0.0, 1.0, 2.0 and $3.0 \mathrm{mg} \mathrm{L}^{-1}$ of 2,4-dichlorophenoxiacetic acid (2,4-D), with 0.0 and $1.0 \mathrm{mg} \mathrm{L}^{-1}$ of 6-benzyladenine (BA), and 30 and $60 \mathrm{~g} \mathrm{~L}^{-1} \mathrm{su}^{-}$ crose. Cultures were incubated either under $16 \mathrm{~h}$ light $\left(38 \mu \mathrm{mol} \mathrm{m} \mathrm{m}^{-2} \mathrm{~s}^{-1}\right)$ and $\mathbf{8 h}$ dark, or kept in complete darkness, for a total of 80 treatments. Callus formation was detected 4 days (d) after beginning the culture (DABC) under light conditions and $5 \mathrm{~d}$ in dark conditions, independently of the treatment, except where plant growth regulators (PGR) were not added and in those supplemented only with BA. SE formation was observed at 100 DDIC; this process was favored in embryogenic calli induced with MS-25, $60 \mathrm{~g} \mathrm{~L}^{-1}$ of sucrose, $3.0 \mathrm{mg} \mathrm{L}^{-1}$ of 2,4-D and 1.0 $\mathrm{mg} \mathrm{L}^{-1}$ of BA, and complete darkness. All SE germinated on the MS-50 medium supplemented with $60 \mathrm{~g} \mathrm{~L}^{-1}$ sucrose and $8 \mathrm{~g} \mathrm{~L}^{-1}$ agar, without PGR. With this protocol it is posible to regenerate complete plants of A. angustifolia in 140 DABC.

Index words: Agave angustifolia, somatic embryos, 2,4-dichlorophenoxia-cetic acid, 6-benzyladenine.

\section{INTRODUCCIÓN}

La familia Agavaceae posee un amplio número de especies de importancia económica por que constituyen una fuente renovable de alimento, azúcares, almíbar, fibras, celulosa, sapogeninas, ensilado para ganado, productos farmacéuticos, bebidas, plantas ornamentales y otros productos más (Madrigal-Lugo et al., 1989). Dentro de esta familia se encuentra el agave mezcalero (Agave angustifolia Haw), utilizado en varios estados de la República Mexicana para la elaboración de licores como mezcal o bacanora, actividad que ha provocado su sobreexplotación $y$, en consecuencia, disminución de las poblaciones silvestres de esta especie (Barraza et al., 2006). A. angustifolia se ha propagado convencionalmente en forma asexual por separación de hijuelos, los cuales se desarrollan de rizomas producidos por cultivos establecidos en campo por varios años. Otra forma eficiente de propagación asexual es mediante la micropropagación o cultivo in vitro. Con esta técnica recientemente se reportó el enraizamiento de brotes obtenidos in vitro a partir de segmentos de médula de tallo de A. angustifolia (Enríquez et al., 2005). El mejoramiento genético de esta especie por técnicas convencionales es complicado por el largo tiempo requerido (10 a 20 años) para producir semillas, periodo característico de los agaves; además los pentaploides $(2 \mathrm{n}=5 \mathrm{x}=60)$ presentan 
infertilidad (Robert et al., 1987).

La embriogénesis somática es considerada una poderosa herramienta para la regeneración y mejoramiento genético de plantas, que puede ser inducida en forma directa sobre el explante o indirectamente a partir de callo. Este proceso morfogénico se favorece mediante la transferencia de los explantes de un medio de cultivo suplementado con altas concentraciónes de auxinas, a uno libre de este tipo de reguladores del crecimiento (Halperin y Wetherell, 1964).

En el género Agave la mayoría de los protocolos reportados se han orientado a la multiplicación masiva in vitro vía organogénesis (Rodríguez-Garay et al., 1996). Hay estudios que muestran que cada especie de Agave requiere concentraciones y combinaciones particulares de reguladores del crecimiento vegetal para lograr una eficiente regeneración de vitroplantas (Martínez-Palacios et al., 2003; Nikam et al., 2003; Domínguez et al., 2008; Ramírez-Malagón et al., 2008). Asimismo, la respuesta depende del tipo de explante; por ejemplo, Powers y Backhaus (1989) reportaron la propagación in vitro de $A$. arizonica Gentry \& Weber a partir de secciones de hoja. Por su parte, Groenewald et al. (1977) lograron la producción de estructuras parecidas a embriones somáticos al usar fragmentos de semillas como explantes en una especie de Agave, pero la embriogénesis somática no fue confirmada. Rodríguez-Garay et al. (1996) y Martínez-Palacios et al. (2003) reportaron embriogénesis somática en A. victoriareginae Moore, a partir de explantes de hoja y segmentos de tallo. Santacruz-Ruvalcaba et al. (1999) lograron la propagación in vitro de $A$. parrasana Berger a través de brotes axilares, y Nikam et al. (2003) lograron inducir embriones somáticos y la regeneración de A. sisalana a partir de bulbillos de inflorescencias. Sin embargo, en A. angustifolia Haw no hay reportes que indiquen su regeneración in vitro a través de embriogénesis somática al utilizar ejes embrionarios cigóticos como explantes.

Los objetivos en este trabajo de investigación fueron: 1) Evaluar el efecto de dos concentraciones de las sales inorgánicas del medio MS, dos niveles de sacarosa, cinco niveles de ácido 2,4-diclorofenoxiacético, dos niveles de 6-benciladenina, y dos condiciones de iluminación (luz y oscuridad), en la inducción de callo embriogénico en $A$. angustifolia Haw; y 2) Promover la formación de embriones somáticos en callos embriogénicos mediante la reducción de la concentración original del medio MS, y del nivel del ácido 2,4-diclorofenoxiacético.

\section{MATERIALES Y MÉTODOS}

\section{Inducción de callo embriogénico}

Como material vegetativo se usaron semillas colectadas de plantas silvestres fenotípicamente promisorias de agave mezcalero (Agave angustifolia Haw) localizadas en Zumpahuacán, Estado de México. Las semillas se desinfectaron superficialmente en forma secuencial, a chorro de agua corriente y jabón antibacterial Dial ${ }^{\circledR}$ por 15 min; después se sumergieron por 1 min en etanol $96 \%$, 15 min en hipoclorito de sodio $(\mathrm{NaClO}) 1 \%$, y finalmente dentro de una campana de flujo laminar se enjuagaron tres veces con agua destilada esterilizada.

Después de desinfectar las semillas, se extrajeron los ejes embrionarios cigóticos (EC) (Figura 1A) y se colocaron cinco por frasco de vidrio de $145 \mathrm{~mL}$ con $25 \mathrm{~mL}$ de medio de cultivo. Cada EC se consideró como una repetición, y se usaron 10 EC por tratamiento. El medio de cultivo se formuló con las sales inorgánicas del medio MS (Murashige y Skoog, 1962), suplementado con las vitaminas L2 descritas por Phillips y Collins (1979). En todas las etapas, el pH del medio de cultivo se ajustó a $5.7 \pm 0.1$ y se solidificó con 8 $\mathrm{g} \mathrm{L}^{-1}$ de agar (Sigma $\left.{ }^{\circledR}\right)$. Posteriormente se esterilizaron los frascos con el medio de cultivo en una autoclave vertical (AESA®) por $20 \mathrm{~min}$, a $121^{\circ} \mathrm{C}$ y $1.1 \mathrm{~kg} \mathrm{~cm}^{-2}$ de presión.

Para inducir el callo embriogénico, se probó el efecto del medio MS a dos concentraciones, 25 y $100 \%$ (MS-25 y MS-100) combinadas con 30 ó $60 \mathrm{~g} \mathrm{~L}^{-1}$ de sacarosa, con 0.0 , 0.5, 1.0, 2.0 ó $3.0 \mathrm{mg} \mathrm{L}^{-1}$ de ácido 2,4-diclorofenoxiacético (2,4-D), 0.0 ó $1.0 \mathrm{mg} \mathrm{L}^{-1}$ de 6-benciladenina (BA), y con dos condiciones de iluminación: $16 \mathrm{~h}$ luz y $8 \mathrm{~h}$ de oscuridad, con luz provista por lámparas de luz blanca fluorescentes $\left(38 \mu \mathrm{mol} \mathrm{m} \mathrm{m}^{-2} \mathrm{~s}^{-1}\right.$ ), y oscuridad completa. Se evaluó un total de 80 tratamientos con 10 repeticiones cada uno; como testigos se consideraron los tratamientos sin reguladores del crecimiento vegetal (RCV). Los explantes fueron incubados a $25 \pm 1{ }^{\circ} \mathrm{C}$.

\section{Formación de embriones somáticos (ES)}

Para inducir la formación de ES, todos los callos embriogénicos previamente obtenidos en los tratamientos evaluados fueron transferidos al medio MS a $50 \%$ de su concentración original (MS-50), suplementado con $0.1 \mathrm{mg}$ $\mathrm{L}^{-1}$ de 2,4-D y $30 \mathrm{~g} \mathrm{~L}^{-1}$ de sacarosa, en condiciones de luz $\mathrm{u}$ oscuridad, según el tratamiento en el que se había inducido el callo embriogénico.

A los $70 \mathrm{~d}$ de incubación se contó el número de callos embriogénicos y de ES formados en cada tratamiento. Los datos fueron analizados mediante un arreglo factorial y una prueba de F $(\mathrm{P} \leq 0.05)$ con el paquete estadístico Minitab Inc. (Hair et al., 1998). 


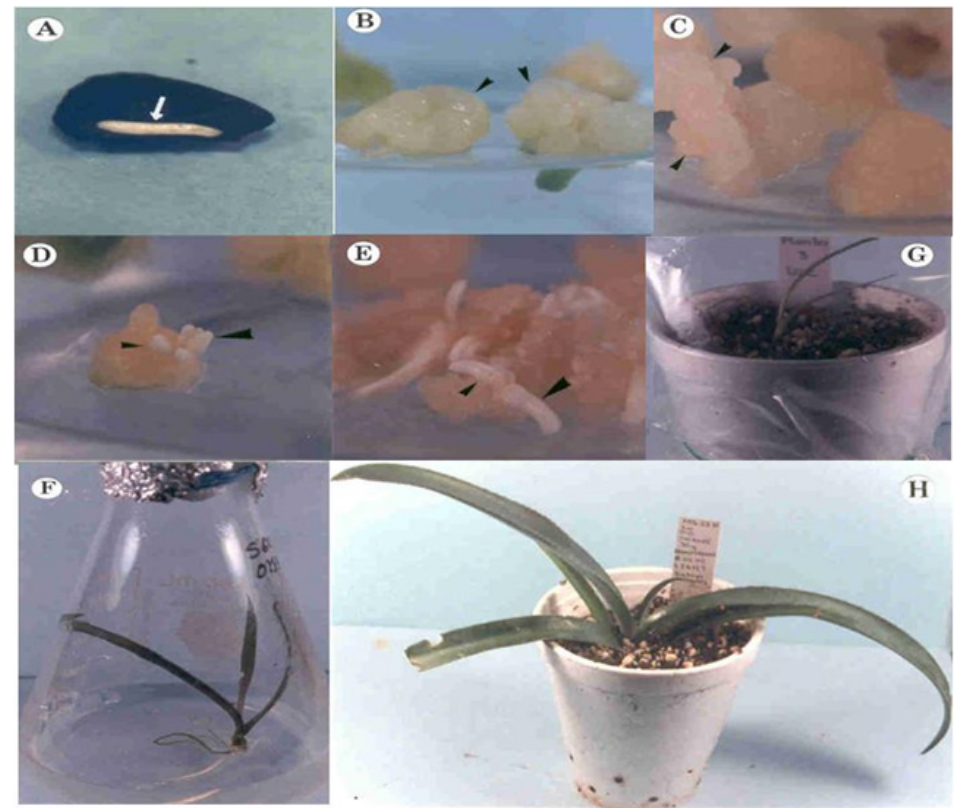

Figura 1. Regeneración de plantas de Agave angustifolia Haw, vía embriogénesis somática y su adaptación a suelo. A) Eje embrionario cigótico (flecha blanca) extraído de la semilla. B) Callos compactos de color blanco-amarillentoperlado a 40 días después de iniciado el cultivo (DDIC). C) Aspecto de los callos embriogénicos de consistencia friable (flechas). D) Embriones somáticos en fase de torpedo (cabezas de flecha) formados en condiciones de luz en el tratamiento MS-100, $60 \mathrm{~g} \mathrm{L-1}$ de sacarosa, $3.0 \mathrm{mg} \mathrm{L-1}$ de 2,4-D y $0.0 \mathrm{mg}$ L-1 de BA a los 80 DDIC. E) Embriones somáticos en fase cotiledonar (cabezas de flecha) en condiciones de oscuridad a los 100 DDIC, proveniente de un callo inducido en el tratamiento MS-25, $60 \mathrm{~g} \mathrm{~L}-1$ de sacarosa, $3.0 \mathrm{mg} \mathrm{L}-1$ de 2,4-D y $1.0 \mathrm{mg} \mathrm{L}-1$ de BA. F) Aspecto de una planta de $A$. angustifolia regenerada a partir de un ES, $40 \mathrm{~d}$ después de transferido al medio de cultivo para su germinación y a 140 DDIC. G) Vitroplanta en etapa de adaptación a los 180 DDIC. H) Vitroplanta adaptada a condiciones medio ambientales a los 202 DDIC.

\section{Germinación de embriones somáticos (ES) y adaptación de plantas regeneradas in vitro}

Para la germinación de los ES se utilizó el medio MS50 sin RCV, suplementado con $15 \mathrm{~g} \mathrm{~L}^{-1}$ de sacarosa $\mathrm{y}$ solidificado con $8 \mathrm{~g} \mathrm{~L}^{-1} \mathrm{de}$ agar.

Las plantas de A. angustifolia regeneradas in vitro, vía ES, fueron lavadas con agua común para eliminar los residuos del medio de cultivo y se colocaron en vasos de unicel de $300 \mathrm{~mL}$ llenados con una mezcla de agrolita y composta (relación de 3:1) como sustrato. Los vasos fueron cubiertos con bolsas blancas de polietileno por un periodo de $21 \mathrm{~d}$, a las que gradualmente se les hicieron perforaciones a fin de incrementar el intercambio gaseoso y robustecer a las plantas, antes de transferirlas a condiciones de invernadero rústico.

\section{RESULTADOS Y DISCUSIÓN}

\section{Inducción de callo embriogénico}

En el género Agave las respuestas morfogénicas in vitro son variadas y dependen del genotipo, del tipo y concentración de los RCV utilizados (Ramírez-Malagón et al., 2008). Así, Groenewald et al. (1977) lograron aumentar la tasa de inducción de callo en especies de Agave al incrementar el nivel de 2,4-D en presencia de cinetina, mientras que en A. fourcroydes (Robert et al., 1987), A. victoriaereginae (Martínez-Palacios et al., 2003) y en otras plantas monocotiledoneas ( $\mathrm{Li}$ et al., 2006), las bajas concentraciones de citocininas en el medio de cultivo, particularmente BA, favorecieron la inducción y crecimiento de callo.

En el presente trabajo se observó la inducción de callo a partir de EC (Cuadro 1) con cualquiera de las concentracion es de 2,4-D evaluadas. Este proceso morfogénico inició con el aumento de tamaño de los explantes (EC) en forma de bellota, a los 4 días (d) después de iniciado el cultivo (DDIC) en condiciones de luz y a los $5 \mathrm{~d}$ en condiciones de oscuridad. Se detectó la formación de dos tipos de callos: unos de color blanco-amarillo perlado y de consistencia dura (Figura 1B), y otros de color-blanco cremoso, de consistencia suave y friable (Figura 1C). La coloración blanco-amarillo perlado predominó en los explantes cultivados bajo condiciones de luz, mientras que el blancocremoso en los cultivados en oscuridad. La consistencia de los callos de color blanco-cremoso facilitó su manejo para realizar subcultivos, y así continuar su crecimiento.

El mayor crecimiento de callo se registró en los tratamientos suplementados con 2.0 y $3.0 \mathrm{mg} \mathrm{L}^{-1}$ de $2,4-\mathrm{D}$, 
sobre todo cuando contenían $1.0 \mathrm{mg} \mathrm{L}^{-1}$ de $\mathrm{BA}$; los callos obtenidos a los 60 DDIC en los tratamientos formulados con MS-25, bajo las concentraciones y combinaciones óptimas antes señaladas, pasaron de $1.2 \mathrm{~g}$ a $2.5 \mathrm{~g}$ a los 140 DDIC. En contraste, en el tratamiento en donde sólo se adicionó BA no se logró la inducción de callo; únicamente se desarrolló la parte apical de la planta pero sin crecimiento de raíz, probablemente debido a que las citocininas favorecen principalmente la formación de brotes (Vidalie, 1986).

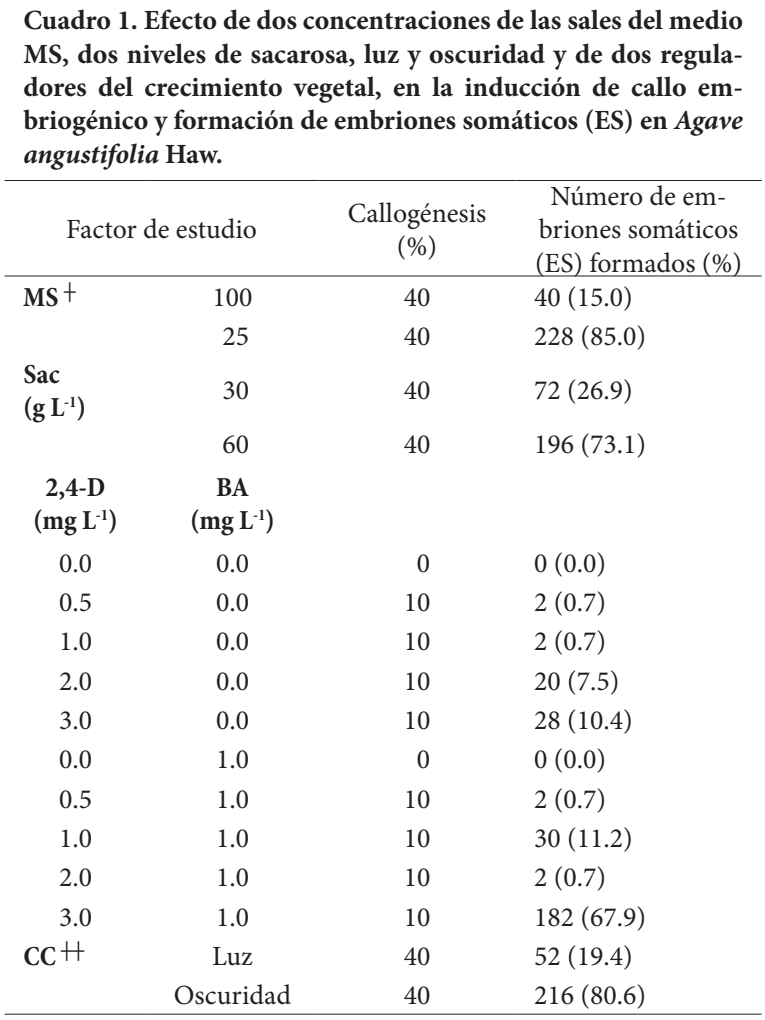

+ MS = Murashige y Skoog, (1962). + CC = condiciones de iluminación.

En los tratamientos sin RCV los EC germinaron en 2 ó 3 DDIC, tanto en luz como en oscuridad. Estos explantes posteriormente formaron plántulas de 4 a $6 \mathrm{~cm}$ de altura con dos o tres hojas, a los 45 DDIC. En los tratamientos testigo no se observó formación de callo, aún después de 120 DDIC. En contraste, la inducción de callo embriogénico sólo fue posible en los tratamientos suplementados con 2,4$\mathrm{D}$, con o sin $\mathrm{BA}$, independientemente de la concentración de las sales del medio (MS-25 o MS-100), del nivel de sacarosa o de si crecieron en luz u oscuridad, condiciones en las que la inducción de callo varió fue de 10 a $40 \%$ (Cuadro 1). El análisis estadístico de los cinco factores con respecto a la inducción de callo embriogénico, mostró que todos los factores principales fueron estadísticamente significativos (Cuadro 2). El 2,4-D es un regulador sintético del crecimiento que puede actuar como inductor efectivo de callo embriogénico (Pierik, 1990), probablemente porque ejerce un fuerte estrés sobre las células del explante y en repuesta éstas adquieren capacidad embriogénica en diferentes grados, como fue reportado recientemente por Kikuchi et al. (2006). Así mismo, la interacción de los factores evaluados fueron significativas, con excepción de la interacción de los factores B x C x D (Cuadro 2).

\section{Formación de embriones somáticos (ES)}

En los tratamientos suplementados con 2,4-D, la capacidad embriogénica de los callos inducidos en el medio MS-25 fue casi seis veces mayor (85\%) que la obtenida con el medio MS-100 (15\%) (Cuadro 1). Al parecer, es necesario un equilibrio de los iones amonio y nitrato en el medio de cultivo, principalmente con una baja concentración de las dos formas, para favorecer la inducción de callo (ArzateFernández et al., 1997); posteriormente este equilibrio acentúa la formación de ES.

Se ha reportado que la adición de carbohidratos estimula la histodiferenciación (Ramsay et al., 2003). Según Körbes y Droste (2005), la concentración de sacarosa puede afectar la inducción morfogénica, como fuente nutritiva y como regulador del potencial osmótico del medio de cultivo. En

\begin{tabular}{|c|c|c|c|c|c|}
\hline $\begin{array}{l}\text { Fuente de } \\
\text { variación }\end{array}$ & $\begin{array}{c}\text { Grados de } \\
\text { libertad }\end{array}$ & $\begin{array}{l}\text { Suma de } \\
\text { cuadrados }\end{array}$ & $\begin{array}{c}\text { Cuadrados } \\
\text { medios }\end{array}$ & $\mathrm{F}$ & $P(0.05)$ \\
\hline $\mathrm{RC}(\mathrm{A})$ & 9 & 46.685 & 5.187 & 70.55 & $0.0000^{\star}$ \\
\hline MS (B) & 1 & 4.112 & 4.112 & 55.92 & $0.0000^{\star}$ \\
\hline $\operatorname{Sac}(\mathrm{C})$ & 1 & 1.195 & 1.195 & 16.25 & $0.0001^{\star}$ \\
\hline CC (D) & 1 & 2.229 & 2.229 & 30.32 & $0.0000^{\star}$ \\
\hline \multicolumn{6}{|l|}{ Interacciones } \\
\hline$A \times B$ & & & & & $0.0000^{*}$ \\
\hline $\mathrm{A} \times \mathrm{C}$ & & & & & $0.0000^{*}$ \\
\hline$A \times D$ & & & & & $0.0000^{*}$ \\
\hline $\mathrm{B} \times \mathrm{C}$ & & & & & $0.0046^{\star}$ \\
\hline$B \times D$ & & & & & $0.0000^{*}$ \\
\hline $\mathrm{C} \times \mathrm{D}$ & & & & & $0.0025^{\star}$ \\
\hline $\mathrm{A} \times \mathrm{B} \times \mathrm{C}$ & & & & & $0.0000^{*}$ \\
\hline$A \times B \times D$ & & & & & $0.0000^{*}$ \\
\hline$A \times C \times D$ & & & & & $0.0000^{*}$ \\
\hline$B \times C \times D$ & & & & & $0.9603 \mathrm{~ns}$ \\
\hline$A \times B \times C \times D$ & & & & & $0.0000^{\star}$ \\
\hline
\end{tabular}


el presente estudio, la formación de ES se incrementó en 2.7 veces (196 vs. 72) en los callos embriogénicos obtenidos en el medio con $60 \mathrm{~g} \mathrm{~L}^{-1}$ de sacarosa, con respecto al medio con $30 \mathrm{~g} \mathrm{~L}^{-1}$ (Cuadro 1).

En los tratamientos donde se usó 2,4-D combinado con $1.0 \mathrm{mg} \mathrm{L}^{-1}$ de BA, la capacidad embriogénica expresada fue mayor que en ausencia de BA porque se formó un total de 216 ES (80.6\%), mientras que en los tratamientos que contenían 2,4-D sin BA sólo se formaron 52 ES (19.4\% del total de los ES obtenidos). El mayor número de ES formados (182) fue obtenido en el tratamiento con $3 \mathrm{mg} \mathrm{L}^{-1}$ de 2,4-D y $1 \mathrm{mg} \mathrm{L}^{-1}$ de BA, como se muestra en el Cuadro 1.

Según Groenewald et al. (1977), al reducir en cinco veces la concentración del 2,4-D se logra inducir morfogénesis en callos de Agave cultivados in vitro. En cambio, una exposición prolongada de los explantes al 2,4-D afecta el desarrollo de la zona meristemática de los ES, cuya diferenciación celular inicia desde su estadio globular. Además, en este estadio el transporte polar de la auxina es esencial para establecer la polaridad del ES, la cual puede ser afectada si existe un incremento o exposición prolongada de auxina (Arzate-Fernández et al., 2008). En esta investigación, los callos embriogénicos inducidos fueron sometidos a una concentración de $0.1 \mathrm{mg} \mathrm{L}^{-1}$ de 2,4$\mathrm{D}$, que es una concentración reducida de este regulador del crecimiento vegetal, lo cual pudo haber favorecido la formación de ES independientemente de la presencia de BA.

Arzate-Fernández et al. (1997 y 2008) reportaron que el uso de una fase oscura es un paso importante para la inducción de callo en Lilium longiflorum y Strelitzia reginae. También Morini et al. (2000) señalaron que las condiciones de oscuridad favorecen la inducción de callo embriogénico en membrillo (Cydonia oblonga M.), para posteriormente inducir la formación de ES bien formados. En el presente trabajo, los EC respondieron de manera muy similar a las condiciones de luz u oscuridad; sin embargo, los EC incubados en oscuridad alcanzaron mayor eficiencia en la inducción de callo y en la formación de ES. Es posible que el efecto del 2,4-D mejore el estímulo morfogénico de explantes cultivados en oscuridad, debido a que la degradación de esta auxina es más lenta en esas condiciones (Arzate-Fernández et al., 1997).

\section{Germinación de embriones somáticos (ES) y adaptación de plantas regeneradas in vitro}

Los ES en fase cotiledonar (Figura 1, D y E) obtenidos fueron transferidos al medio de germinación descrito previamente, donde se logró $100 \%$ de germinación. La germinación inició con el desarrollo de la parte apical y posteriormente del sistema radicular; estas vitroplantas alcanzaron una altura de 4 a $7 \mathrm{~cm}$ a los $40 \mathrm{~d}$ (Figura 1F). Todas las plántulas regeneradas in vitro vía ES, lograron adaptarse (Figura 1, G y H) a las condiciones de invernadero rústico, después de $40 \mathrm{~d}$ de la transferencia al medio de germinación.

\section{CONCLUSIONES}

Fue posible la formación de embriones somáticos, previa inducción de callos embriogénicos, al utilizar como explantes a ejes embrionarios cigóticos de Agave angustifolia Haw. Los factores aquí evaluados fueron importantes en la inducción de callos embriogénicos y en la formación de embriones somáticos de esta especie. Las altas concentraciones de 2,4-D (2.0 a $\left.3.0 \mathrm{mg} \mathrm{L}^{-1}\right)$ favorecen la inducción de callos embriogénicos con una alta capacidad de formación de embriones somáticos. La posterior reducción de la concentración de 2,4-D a $0.1 \mathrm{mg}$ $\mathrm{L}^{-1}$ favorece la formación de embriones somáticos.

El mejor tratamiento para la inducción de callo embriogénico y de embriones somáticos fue: MS a $25 \%$ de su concentración original, suplementado con $60 \mathrm{~g} \mathrm{~L}^{-1}$ de sacarosa, $3.0 \mathrm{mg} \mathrm{L}^{-1}$ de 2,4-D y $1.0 \mathrm{mg} \mathrm{L}^{-1}$ de BA, en condiciones de completa oscuridad.

Todas las plantas regeneradas (216) a través de embriones somáticos se adaptaron a condiciones ambientales del invernadero rústico.

\section{AGRADECIMIENTOS}

A la Coordinación General de Investigación de la Universidad Autónoma del Estado de México, por el financiamiento parcial otorgado a través del programa "Enlace de Investigación".

\section{BIBLIOGRAFÍA}

Arzate-Fernández A-M, J L Piña-Escutia, H A Zavaleta-M (2008) Inducción de proembriones somáticos en ave de paraíso (Strelitzia reginae Banks). Rev. Fitotec. Mex. 31:183-186.

Arzate-Fernández A-M, T Nakazaki, Y Okumoto, T Tanisaka (1997) Efficient callus induction and plant regeneration from filaments with anther in Lily (Lilium longiflorum Thunb.). Plant Cell Rep. 16:836-840.

Barraza A, F L Sánchez, M Robert, M Esqueda, A Gardea (2006) Variabilidad genética en Agave angustifolia Haw de la Sierra Sonorense, México, determinada con marcadores RFLP. Rev. Fitotec. Mex. 29:1-8.

Domínguez M S, A G Alpuche, N L Vasco, E P Molphe (2008) Efecto de citocininas en la propagación in vitro de agaves mexicanos. Rev. Fitotec. Mex. 31:317-322.

Enríquez V J R, G Carrillo, J L Rodríguez (2005) Sales inorgánicas y ácido indolbutírico en el enraizado in vitro de brotes de Agave angustifolia. Rev. Fitotec. Mex. 28:175-178.

Groenewald E G, D C J Wessels, A Koeleman (1977) Callus formation 
and subsequent plant regeneration from seed tissue of an Agave species (Agavaceae). Z. Pflanzenphysiologie Bd. 815:369-373.

Hair J F, R E Anderson, R LTatham, W C Black (1998) Multivariate Data Analysis. 5th ed. Prentice Hall. USA. pp:239-322.

Halperin W, D F Wetherell (1964) Adventative embryony in tissue cultures of will carrot (Daucus carota) Amer. J. Bot. 51:274-283.

Kikuchi A, N Sanuki, K Higashi, T Koshib, H Kamada (2006) Abscisic acid and stress treatment are essential for the acquisition of embryogenic competence by carrot somatic cells. Planta 223:637645.

Körbes A P, A Droste (2005) Carbon sources and polyethylene glycol on soybean somatic embryo conversion. Pesq. Agropec. Bras. 40:211216.

Li R, A H Bruneau, R Qu (2006) Improved plant regeneration and in vitro somatic embryogenesis of St Augustinegrass [Stenotaphrum secundatum (Walt.) Kuntze]. Plant Breed. 125:52-56.

Madrigal-Lugo R, F Pineda-Estrada, J L de la O Rodríguez (1989) Agave. In: Handbook of Plant Cell Cult. Ornamental Species. PV Ammirato, DA Evans, WR Sharp, YPS Bajaj (eds). McGraw Hill Publ. Co. New York. pp:206-227.

Martínez-Palacios A, M P Ortega-Larrocea, V M Chávez, R Bye (2003) Somatic embryogenesis and organogenesis of A. victoria-reginae: Considerations for its conservation. Plant Cell Tiss. Org. Cult. 74:135-142.

Morini S, C D'Onofrio, G Bellocchi, M Fisichella (2000) Effect of 2,4-D and light quality on callus production and differentiation from in vitro cultured quince leaves. Plant Cell Tiss. Org. Cult. 63:47-55.

Murashige T, F Skoog (1962) A revised medium for rapid growth and biossays with tabacco tissue cultures. Physiol. Plant. 15:473-497.
Nikam T D, G M Bansude, K C Aneesh Kumar (2003) Somatic embryogenesis in sisal (A. sisalana Perr. ex. Engelm). Plant Cell Rep. 22:188-194.

Phillips G C, G B Collins (1979) In vitro tissue culture of selected legumes and plant regeneration from callus cultures of red clover. Crop Sci. 19:59-64.

Pierik R L M (1990) Cultivo in vitro de las plantas superiores. Ed. MundiPrensa. Madrid, España. pp:209-226.

Powers D E, R A Backhaus (1989) In vitro propagation of Agave arizonica Gentry \& Weber. Plant Cell Tiss. Org. Cult. 16:57-60.

Ramírez-Malagón R, A Borodanenko, L Pérez-Moreno, M D SalasAraiza, H G Nulez-Planius, N Ochoa-Alejo (2008) In vitro propagation of three Agave species used for liquor distillation and three for landscape. Plant Cell Tiss. Org. Cult. 94:201-207.

Ramsay J L, D Galitz, C W Lee (2003) Basal medium and sucrose concentration influence regeneration of Easter Lily in ovary culture. HortScience 38:404-406.

Robert M L, J L Herrera, F Contreras, N K Score (1987) In vitro propagation of Agave fourcroydes Lem (Henequén). Plant Cell Tiss. Org. Cult. 8:37- 48.

Rodríguez-Garay B, Gutiérrez-Mora A, B Acosta-Dueñas (1996) Somatic embryogenesis of Agave victoria-reginae Moore. Plant Cell Tiss. Org. Cult. 46:85-87.

Santacruz-Ruvalcaba F, H Gutiérrez, B Rodríguez (1999) Efficient in vitro propagation of Agave parrasana Berger. Plant Cell Tiss. Org. Cult. 56:163-167.

Vidalie H (1986) Cultivo in vitro. Ed. Científica, S.A de C.V. México, D.F. pp:1-138. 